\title{
Congophilic angiopathy of the brain: a clinical and pathological report on two siblings
}

\author{
RA GRIFFITHS, TF MORTIMER, DR OPPENHEIMER, JMK SPALDING \\ From the Departments of Geriatric Medicine, Neurology and Neuropathology, Radcliffe Infirmary, Oxford \\ and the Department of Pathology, Horton General Hospital, Banbury
}

SUMmARY Clinical and histological accounts are given of a sister and brother, dying aged 61 and 56 years respectively after illnesses lasting 5-6 years marked by a progressive mental and physical disability. The family history suggested transmission by a dominant gene. The histological findings were of a very severe congophilic angiopathy confined to the brain, spinal cord and leptomeninges and giving rise to multiple haemorrhages and softenings. There were, in addition, abundant amyloid-containing "plaques" of various forms, found principally in the hippocampus and cerebellar cortex. The cases are compared with similar cases in the literature, and reasons given for regarding this condition as a separate entity rather than a variant of Alzheimer's disease.

In $1940^{1}$ and $1944^{2}$ Worster-Drought, Greenfield and McMenemey described a family of which 10 members, male and female, over three generations, suffered from a progressive paralysis, associated in most cases with dementia. The onset was usually in the fifth decade, and the mean duration of the illness was about 9 years. Two affected siblings came to necropsy, and showed very similar lesions in the brain, consisting of "hyaline" changes in small blood vessels and peculiar "plaques", up to $100 \mu \mathrm{m}$ in diameter, in the hippocampus and cerebellar cortex. They labelled the condition Familial presenile dementia with spastic paralysis, and regarded it as a new entity, clearly separable from previously described dementing processes. They considered, and rejected, the idea that it was somehow related to Alzheimer's disease. Such a relationship, however, was suspected by later authors, who observed that in cases resembling those described by WorsterDrought et al there was a florid cerebral amyloid angiopathy, not associated with amyloidosis in the rest of the body, recalling, though generally far exceeding, the amyloid angiopathy frequently observed in cases of Alzheimer's disease.

We shall discuss the quesion of-classification later in this paper, having first given a clinical and pathological account of a sister and brother whose illness was clearly the same as that described by Worster-Drought et al. ${ }^{12}$

Address for reprint requests: Dr RA Griffiths, The Radcliffe Infirmary, Oxford OX2 6HE, UK.

Keceived 14 September 1981 and in revised iorm 11 December 1981. Accepted 17 January 1982.

\section{Case reports}

\section{Family history}

The information shown in fig 1 is based on interviews with the wife, daughter (D3) and son-in-law of our patient CB (C9) at the time of his illness in 1971, and on subsequent interviews and correspondence with these and other members of the family. The ages shown in the table for living members of the family refer to June 1978 . As would be expected, there are gaps in our knowledge: for instance, we have been unable to trace the three daughters of B4 (C3, C4 and C5), all of whom would appear to be at risk. They are now of an age at which the family disease, if present, might be expected to declare itself. $\mathrm{C} 1$ has also been untraced and it is not known whether she has any children. The members of the family known to have suffered from neurological disorders are: A The maternal grandmother of our two cases. She was said to have died aged 60 from "creeping paralysis". She was confined to a wheelchair towards the end of her life. B4 Daughter of A, died in 1941 , aged 52. She was said to have had a "brain tumour"; cause of death not known. B5 The mother of our two cases. Her illness started at age 46 , when she began to "walk crooked", and "complained about her head". Two years later she was admitted to a mental hospital. In the following year she was able to "comprehend" her daughter's wedding, but was not well enough to attend. She was unable to walk because of weakness of her legs, and became incontinent of urine. She died in 1938, aged 56 . C6 (our case 1) and C9 (our case 2). Clinical and pathological details are given below.

The available evidence suggests dominant inheritance of a neurological disease, affecting males and females in middle age. No male-to-male transmission has been recorded. It is probable that members of the family who died over the 396 


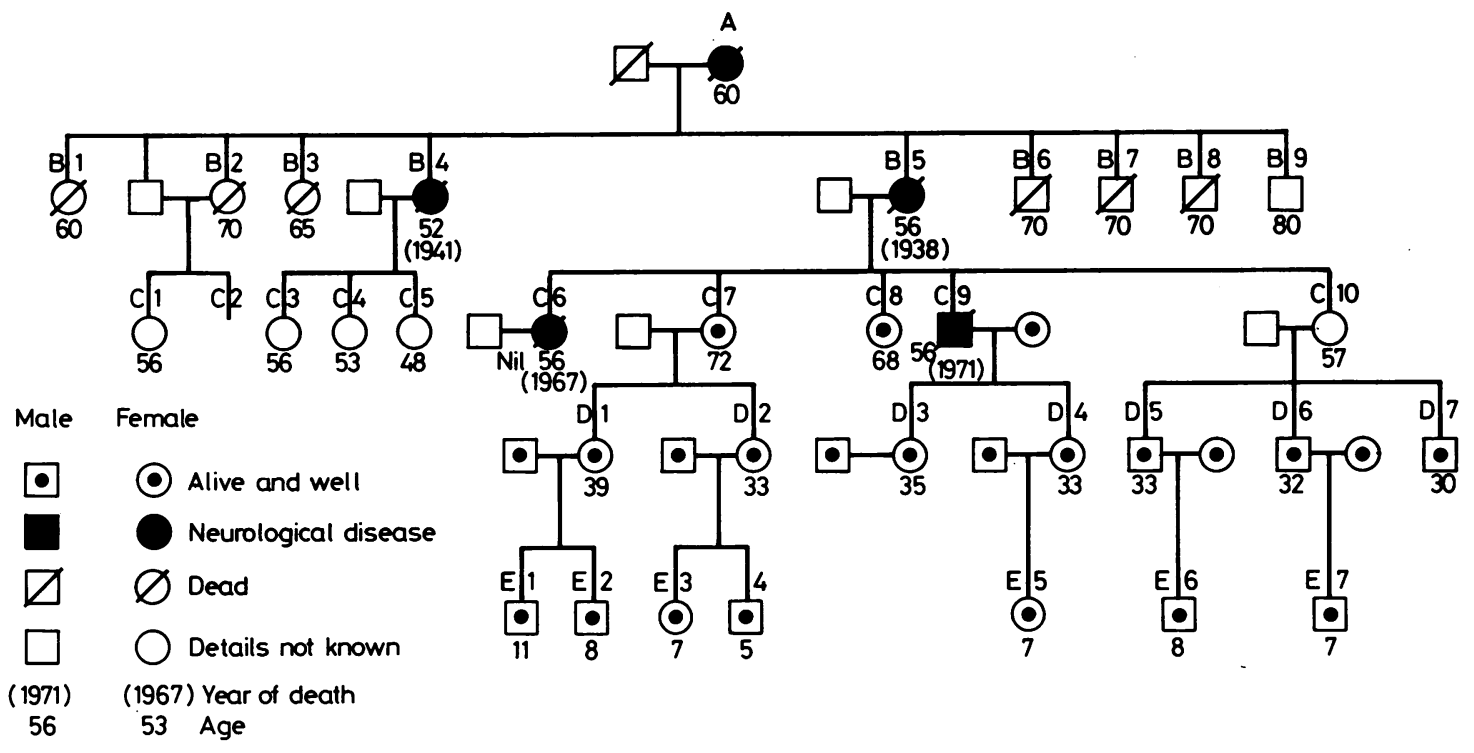

Fig 1 Family tree. Ages of living members refer to 1978. Our cases 1 and 2 are C6 and C9 respectively.

transmitters of the family disease. The daughters of C9 (D3 and D4) have received appropriate genetic counselling.

Case 1 FC (C6 in fig 1). Female, born 1905. Died 1966, aged 61 years. Married, but with no progeny. Nothing is known of her medical history until 1959, when her speech became slurred, and she was heard to say "I am walking just like Mum". In 1960 she was seen by Dr JD Craig at St Bartholomew's Hospital, Rochester, Kent. At this time speech was slurred, and gait was unsteady and somewhat spastic. She had nystagmus on looking to the right, and tremor of the protruded tongue. Tendon reflexes were brisk, abdominal reflexes absent, and there was no incoordination. Blood pressure was $200 / 110 \mathrm{mmHg}$. Lumbar cerebrospinal fluid was normal. In February 1961 her legs gave way in the street, after which she lost consciousness and remained unconscious for about a day. Three days later she did not know her age or the date. She was dysarthric, and spoke in monosyllables. There was nystagmus and ataxia of the limbs, with a left extensor plantar response. In the following month she was admitted to All Saints' Hospital, Chatham. Lumbar puncture at this time showed CSF containing 25 red cells and 10 white cells per $\mathrm{cmm}$, with $50 \mathrm{mg}$ of protein per $100 \mathrm{ml}$. She remained in hospital, and lapsed into a vegetative state, which persisted. Four years later she was bedridden, unresponsive and doubly incontinent, lying in a curled-up attitude, with severe scoliosis and pes cavus. Fundi were normal. There was widespread muscle wasting, affecting particularly the right calf, both quadriceps, and hands. There was increased tone, with exaggerated tendon reflexes, except in the right arm and right ankle. Plantar responses were extensor. Blood pressure was $160 / 100 \mathrm{mmHg}$. She died in December 1966. A postmortem examination was carried out at All
Saints' Hospital, Chatham, by Dr NJH Davidson, who very kindly sent the brain and spinal cord to us.

Case 2 CB (C9 in fig 1). Male, born 1915. Died 1971 aged 56 years. Noted to have kyphosis in his teens. Blood pressure recorded in 1953 as $160 / 100 \mathrm{mmHg}$. No symptoms until February 1965, when he suddenly burst into tears for no apparent reason, except that he was worried about his mother's and his sister's illnesses. In March 1965 he developed some weakness of arms and legs, with unsteadiness of gait, some slurring of speech, and forgetfulness for small domestic matters. He complained of pins and needles in the fingers of both hands. On examination he had a kyphoscoliosis but no pes cavus; mild spastic dysarthria; slight proximal lower limb weakness, slight ataxia of left leg and slight unsteadiness of gait. Muscle tone and reflexes were normal. There was no obvious dementia, but air encephalography showed moderate ventricular dilatation. CSF was normal, under normal pressure. Blood pressure 130/80 mmHg. ECG normal. After this, symptoms and signs fluctuated, following a slow downhill course but without dramatic episodes. Memory and concentration were impaired, and in February 1966 he had to leave his job as a storeman. His gait became slow and shuffing, with loss of associated arm movements. By July 1968,3 years after the onset of the illness, his movements had become very slow. He could walk 10-12 m, with support, before collapsing. He stayed at home, watching television and reading; but was unable to say what he had been reading. He had suffered a transient abducens paresis, but cranial nerves at this time were normal. By December 1969, dementia was obvious. He could not give the date, remember a name and address or a Babcock sentence, or subtract 7 from 100 . He could read, but could not perform written commands. There was dysarthria, with a slight left 
facial weakness, and the tongue protruded to the left. Reflexes were equal and brisk with flexor plantar responses. Sensation appeared to be normal. EEG showed slow dominant activity and a considerable excess of postcentral responsive slow activity. The slow mental and physical deterioration continued. During his last admission he had further cerebellar signs, bilateral grasp reflexes, and increased tone in all limbs, but tendon reflexes were normal, and plantar responses were still flexor. No sensory deficits could be demonstrated. Haematological and biochemical investigations were negative, and the ESR was normal. There were periods of confusion, aggressiveness and impaired consciousness, but no localising signs were found following these episodes. Finally he lay in bed, unresponsive, in a flexed attitude. He developed bronchopneumonia and died in February 1971, aged 56.

To summarise these two cases, noting their similarities and differences: both patients, in their sixth decades, developed a progressive neurological disorder in which weakness, dysarthria and incoordination were early features. Kypho-scoliosis was observed in both cases, but it is not known when it developed in case 1 . Both patients died demented and bedridden, after an illness lasting several years. The striking differences are, first, that whereas in case 2 the course fluctuated, without dramatic exacerbations, in case 1 there was at least one sudden episode, almost certainly due to a cerebellar haemorrhage. This may well be related to the fact that the first patient was hypertensive, whereas the second was not.

\section{Pathology}

Case 1 (FC). No significant changes were observed outside the central nervous system. Externally the brain was unremarkable. On coronal slicing, it showed gross dilatation of both lateral ventricles, attributable to shrinkage of central white matter, which contained scattered ill-defined areas of softening at all levels. The corpus callosum was reduced to a width of 1-2 mm. There was atrophy of both lentiform nuclei and thalami, but the cortical ribbon appeared well preserved. Some of the larger superficial arteries had thickened walls. In the hindbrain, there was a dilated fourth ventricle, and the brainstem and cerebellum were disfigured by a number of brown-coloured softenings, the largest involving the left dentate nucleus and the surrounding white matter. The spinal cord appeared normal.

Histological examination showed several kinds of lesion, as follows: (1) Splitting and disruption of the walls of many small and medium-sized arteries and veins, with partial or complete occlusion of the lumina by necrotic débris, sometimes mixed with thrombus. (2) Residues of old or recent haemorrhages from diseased vessels, and of old or recent infarcts due to vascular occlusion (fig $2 a, b, c)$. (3) Deposition of congophilic material in the walls of diseased vessels; (4) "Plaques" of various types, described below, mainly in the hippocampus and cerebellar cortex; (5) Neurofibrillary tangles, of Alzheimer type, in a few cells of the subiculum and hippocampus. The vascular changes were the most striking. Some of them are shown in figs 3 to 8 . The changes in individual vessels were very varied, but could be tentatively arranged in an oider of severity, which presumably corresponded with a time sequence in their formation, thus: (a) thickening of arteriolar walls, with deposition of amyloid in the media (fig 3). (b) Splitting of the elastic lamina (figs 4 and 5). (c) Laminar necrosis of the media, leading to a major cleavage in the vessel wall (fig 6). (d) Occlusion of the lumen by thrombus and/or necrotic débris (fig 7). (e) Dribbling haemorrhage, leaving deposits of haemosiderin and bilirubin, often mixed with sudanophilic fat (fig 8 ). In addition, the medial walls of some but not all of the affected vessels stained intensely with Oil Red $\mathrm{O}$ in frozen sections.

These changes could be seen in superficial and intrinsic vessels in all parts of the brain and of the spinal cord. In general, the larger arteries were unaffected, or showed the usual changes of mild atheroma. The vertebral arteries, sectioned at several levels, were unremarkable, and contained no congophilic material. Arterioles in the choroid plexuses were unaffected.

Plaques of three main types were encountered in the cerebellar cortex and in Ammon's horn (the word "plaque" is used out of deference to convention. The structures in question are not shaped like discs, as the word might suggest, and have nothing in common with the "plaques" of multiple sclerosis): (a) Globular, almost acellular, deposits of a material staining feebly with Congo red and PAS, and with most silver impregnations, measuring up to $180 \mu \mathrm{m}$ in diameter (fig 9). Some of the larger specimens contained central cores, staining intensely with silver, Congo red and PAS. They did not appear to be related to vessels. Plaques of this type were abundant in the dentate gyrus and in the end-folium of the hippocampus, and were also seen in varying numbers in the pyramidal layer of the hippocampus, in the temporal and occipital white matter, in the granular and molecular layers of the cerebellar cortəx, in the brainstem and in both grey and white matter of the spinal cord. (b) Small clusters of irregular granules, strongly argyrophilic, Congophilic, and PAS positive, resembling the central cores of the preceding type (fig 10). These clusters, which measured no more than $30 \mu \mathrm{m}$ in diameter, were abundant in the pyramidal layer and endfolium of the hippocampus, but were not seen elsewhere in the brain. (c) Poorly-defined acellular areas, up to $100 \mu \mathrm{m}$ in diameter, surrounding capillaries and other small vessels (fig 11). These were occupied by a system of fine radiating fibrils, staining feebly with PAS and Congo red, and were abundant in the granular and molecular layers of the cerebellar cortex. A few were present in the cerebral white matter, but none were seen in cerebral cortex or other areas of grey matter.

Neurofibrillary tangles, indistinguishable from those of Alzheimer's disease, were present in $h_{2}$ sector of the hippocampus (fig. 12) but not in the subiculum or other cortical areas.

There was no convincing evidence of system degeneration in the nervous parenchyma. On both sides there was severe cell loss, with glial scarring, in the inferior olives; but this could be interpreted as a secondary effect of the widespread vascular lesions in the cerebellum. In the cord, there was well-marked degeneration of both crossed and uncrossed corticospinal tracts, the right crossed tract being the worst affected; but this too could be attributed to vascular lesions in the brainstem and upper spinal cord. Severe degeneration was also seen in the posterior spinocerebellar tracts in the thoracic and cervical cord segments; 

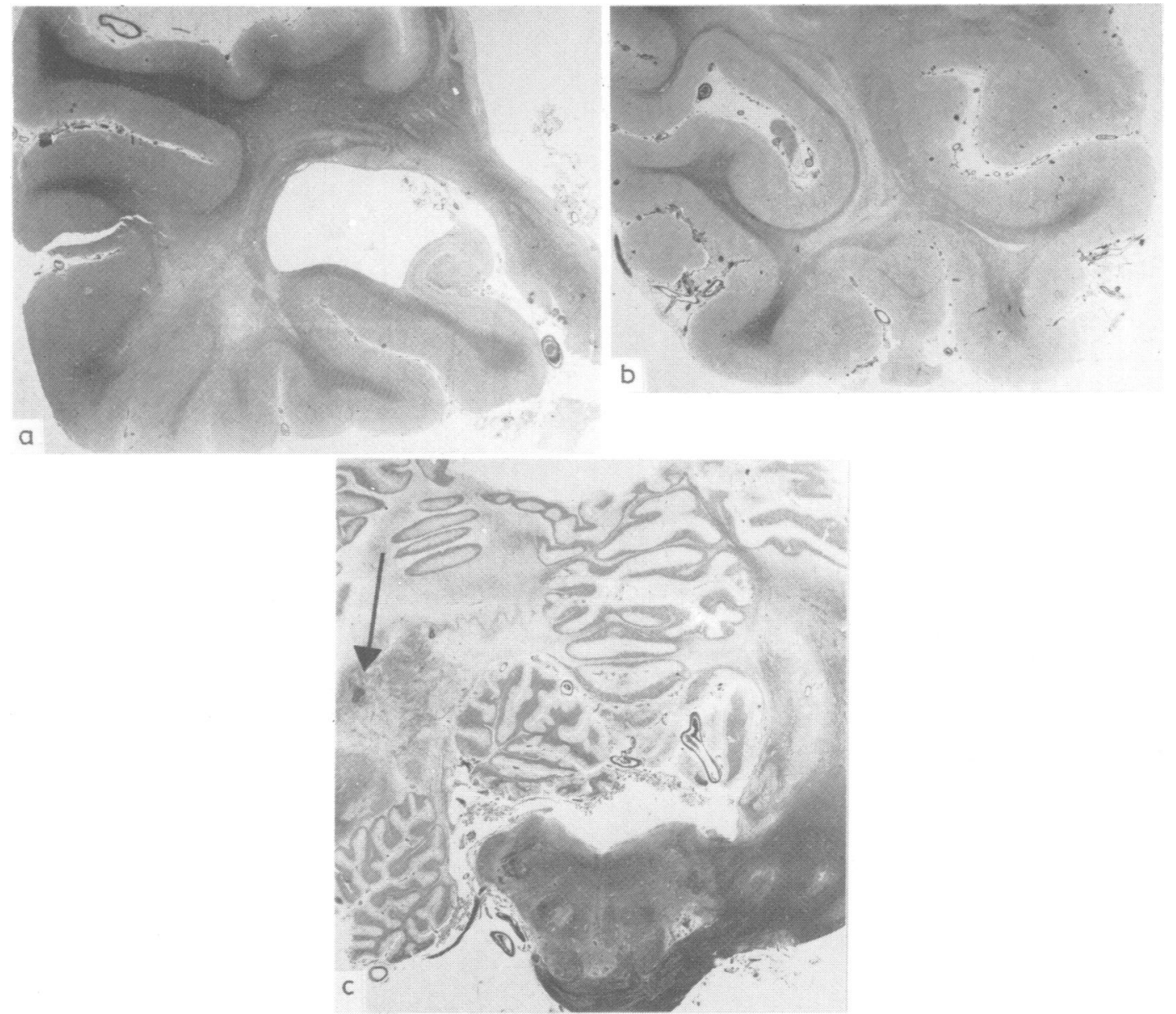

Fig 2 Case 1 Myelin-stained sections, showing rarefactions and Wallerian degeneration. The arrow indicates a fair-sized haemorrhage. (a) temporal lobe, (b) occipital lobe, (c) brainstem and cerebellum.

but there was no obvious depletion of cells in Clarke's columns, or in the accessory cuneate nuclei, and the tract degeneration could plausibly be ascribed to the cumulative effect of small vascular lesions near the surface of the cord. Finally, the cerebral cor'ex, thalamus, basal ganglia, and brainstem appeared normal apart from vascular lesions. In particular, there was no cortical spongy change.

To summarise the pathological findings: there was a congophilic angiopathy, affecting all parts of the brain and spinal cord, and far exceeding in its severity anything seen in classical Alzheimer's disease. This vascular disease had resulted in innumerable haemorrhages and infarcts. In addition, there were plaque-like deposits of amyloid material, almost restricted to Ammon's horn and cerebellar cortex, some having points of resemblance with the typical "plaques" of Alzheimer's disease, but with important differences. There was no evidence of primary neuronal degeneration, and no cortical spongiosis.
Case 2 (CB). The general necropsy findings (TFM) were of a thin elderly man with kyphoscoliosis. There was no wasting of specific muscle groups. The lungs showed oedema and conffuent bronchopneumonia. Other viscera were unremarkable, grossly and microscopically. There was no sign of amyloidosis outside the central nervous system.

The brain showed moderate generalised atrophy. Meninges appeared normal, and the basal arteries showed only mild atheromatous changes. On slicing, irregular, gelatinuous, orange-brown areas, none more than $2 \mathrm{~cm}$ across, were seen in the corpus callosum, centrum ovale, and dentate nuclei of the cerebellum. There was a confluence of such lesions in the roof of the left lateral ventricle. In addition, there were minute cystic grey lesions, looking like old infarcts, scattered through both internal capsules and thalami. The brainstem, spinal cord, cerebellar cortex and white matter were macroscopically normal. 


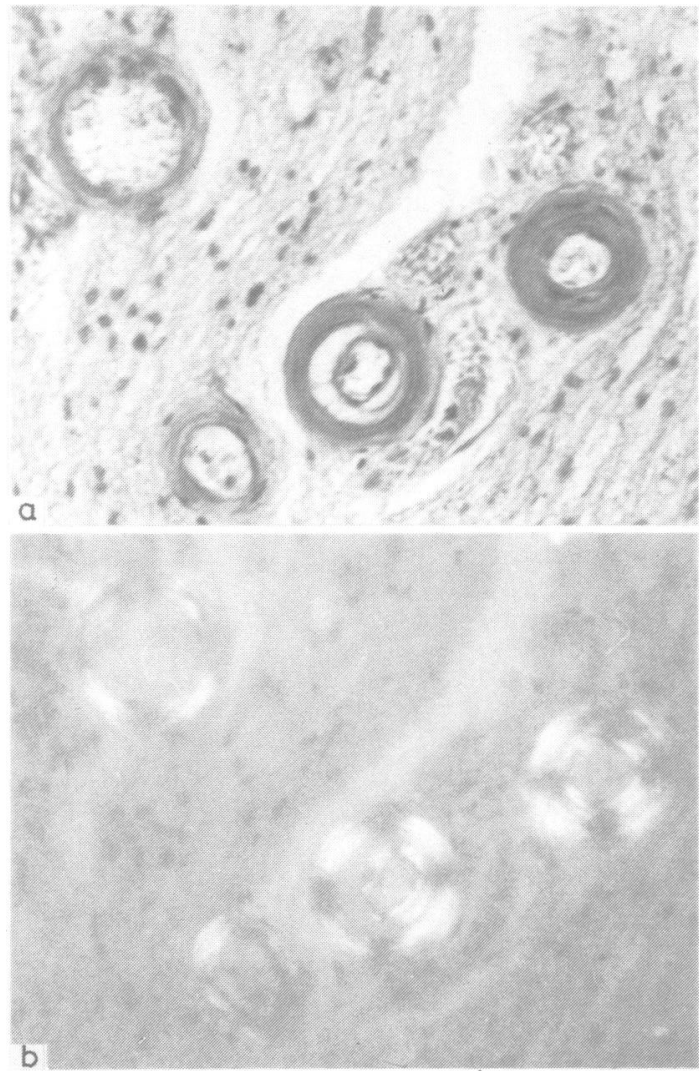

Fig 3 Case 1 Vessels in spinal cord. (a) Congo Red/haematoxylin, (b) same, through crossed Nicols, $\times$ 220.

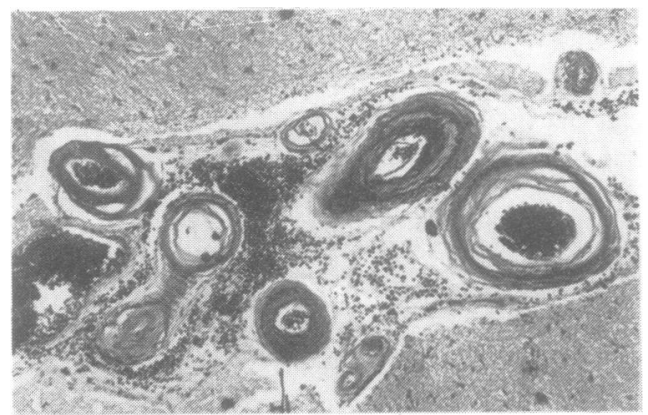

Fig 4 Case 1 Pial vessels in occipital lobe. Elastin/van Gieson, $\times 75$.

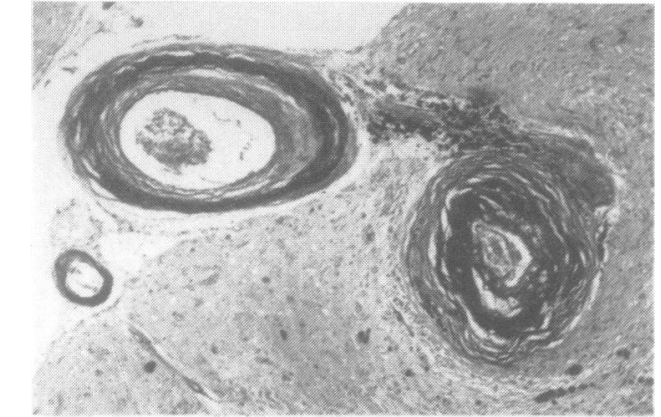

Fig 5 Case 1 Pial vessels in cerebellum, showing splitting of elastica and media. A small old haemorrhage lies between them. PAS, $\times 75$.

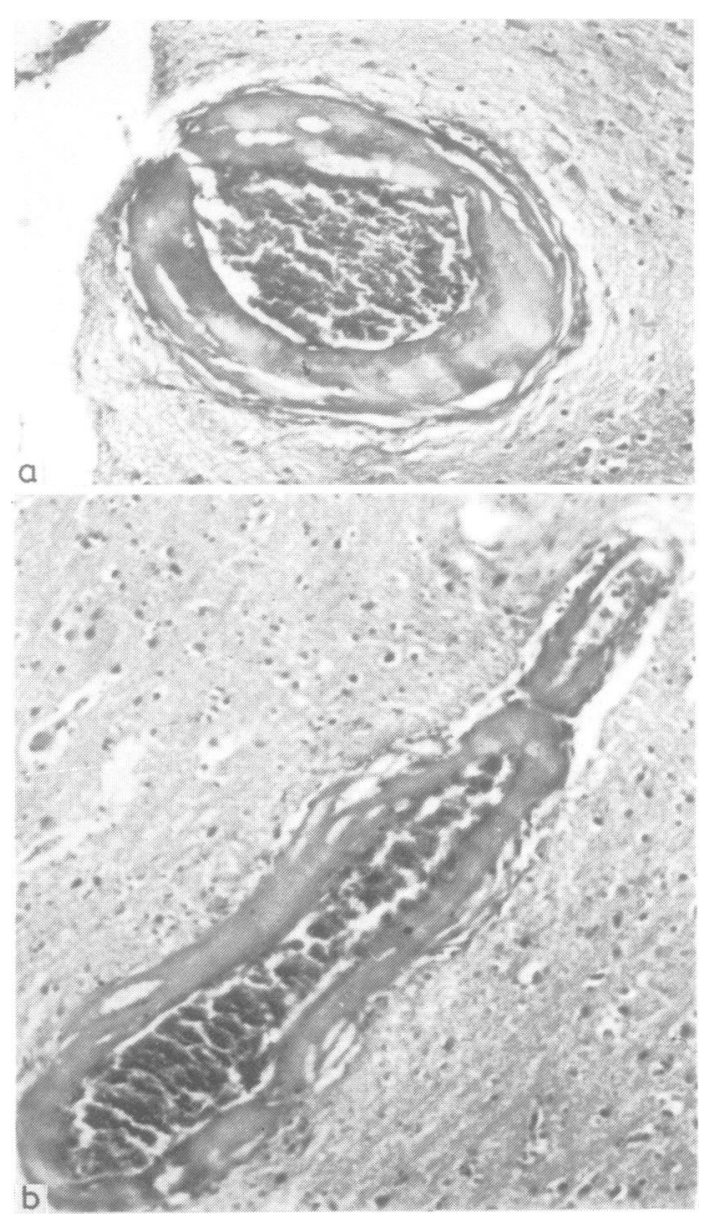

Fig 6 Case 1 (a) \& (b) vessels in temporal cortex, showing medial necrosis. $H \& E, \times 200$. 

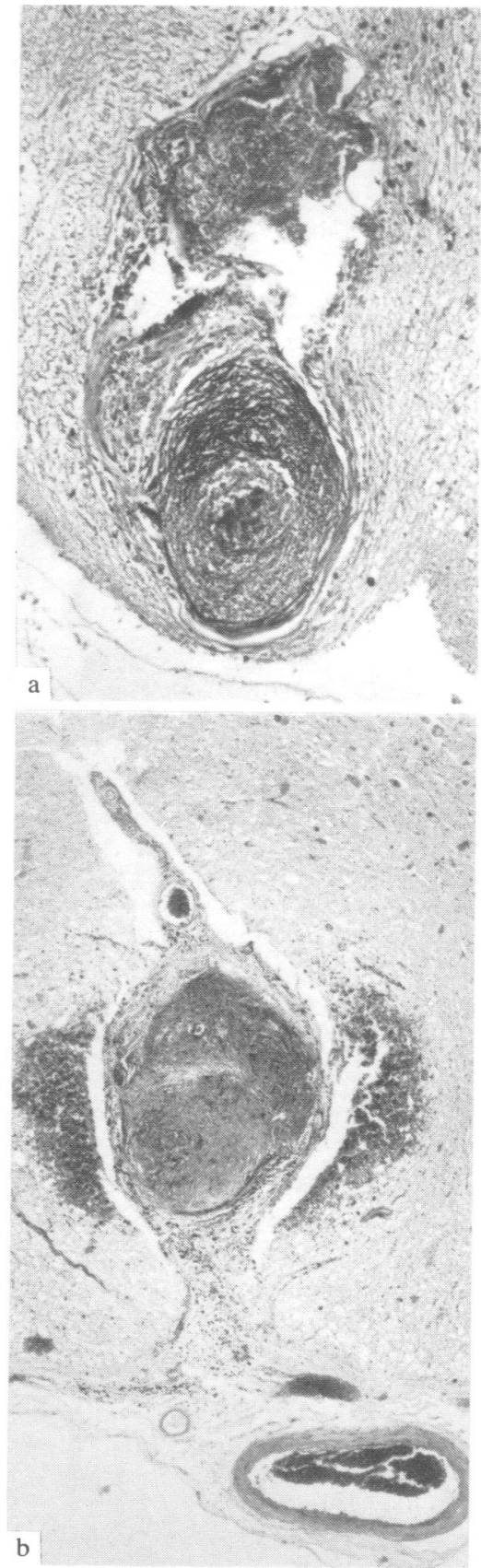

Fig 7 Case 1 (a) vessels probably a vein, with occluded lumen and signs of intra- and extra-mural bleeding. Klüver-Barrera, $\times 65$. (b) occluded vessel, probably a vein, in the anterior median sulcus of the thoracic cord. There is evidence of old subarachnoid haemorrhage and recent haemorrhage into the cord substance on both sides. $H \& E$ $\times 75$.

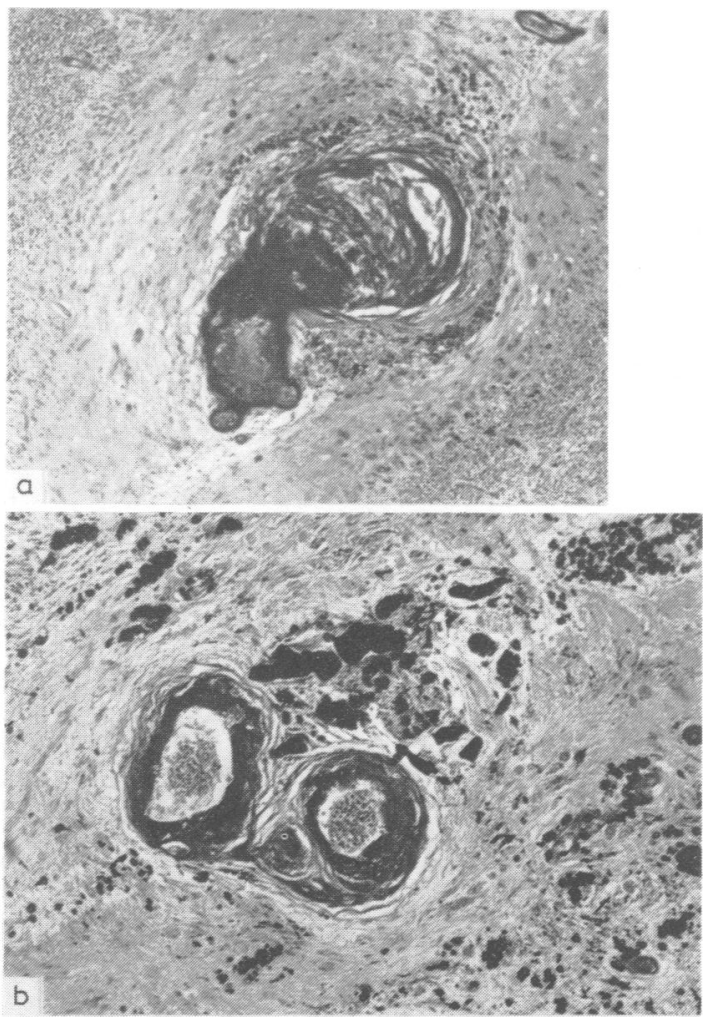

Fig 8 Case 1 Haemorrhages in cerebellum. (a) a ring of siderin phagocytes around an occluded vessel, (b) multiple aggregates of siderin phagocytes in a larger area of haemorrhage. $\bar{P} A \bar{S} \times \overline{7} \overline{5}$.

The histology of the brain resembled that of case 1 in some respects, but differed in others. Vascular changes were of the same kind as in case 1 (see figs $3,4,5$ ), but much less severe. Hyaline thickening of arterioles, and deposition of congophilic material in their medial walls, were seen in all parts. Medial splitting was seen in a few places; thrombosis and medial necrosis were rare; and there were no major haemorrhagic lesions or infarcts. In the areas of naked-eye discoloration, there was a sprinkling of siderin-containing phagocytes, but nowhere any large accumulations of siderin and bilirubin such as were seen in case 1 . Vessels of the spinal cord were relatively unaffected.

Congophilic "plaques" of various types were present, but their distribution differed from that in case 1. Large plaques (corresponding to type $\mathrm{C}$ described above), were abundant in the cerebral white matter, particularly in the corpus callosum and periventricular white matter, and in the granular and molecular layers of the cerebellar cortex (fig 13). They were also present in the dentate nuclei, cerebellar white matter, and some areas of the brainstem including the inferior olives. The pattern of radiating fibrils surrounding small vessels was if anything more marked than in case 1 . 

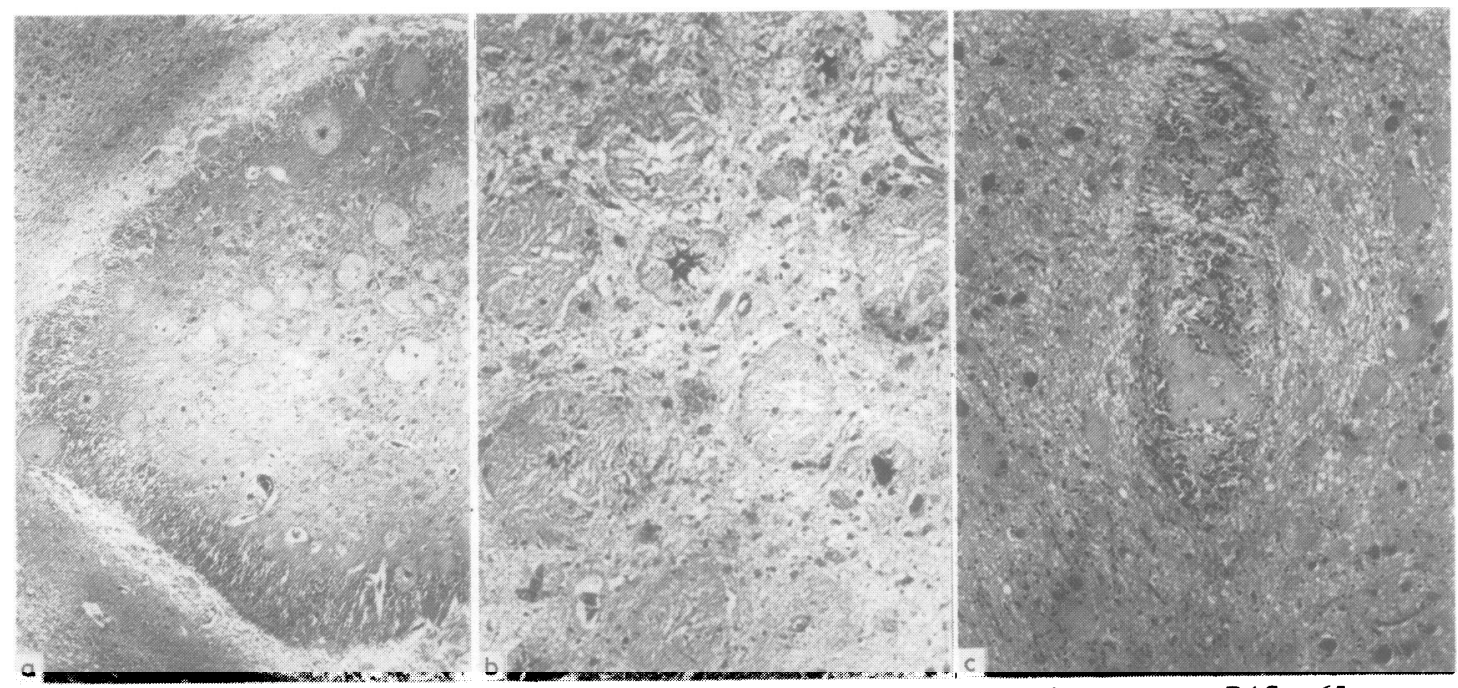

Fig 9 Case 1 “Atypical" plaques. (a) hippocampus, Holmes Silver Stain, $\times 25$. (b) hippocampus, PAS $\times 65$, (c) raphe of midbrain, $H \& E \times 60$.

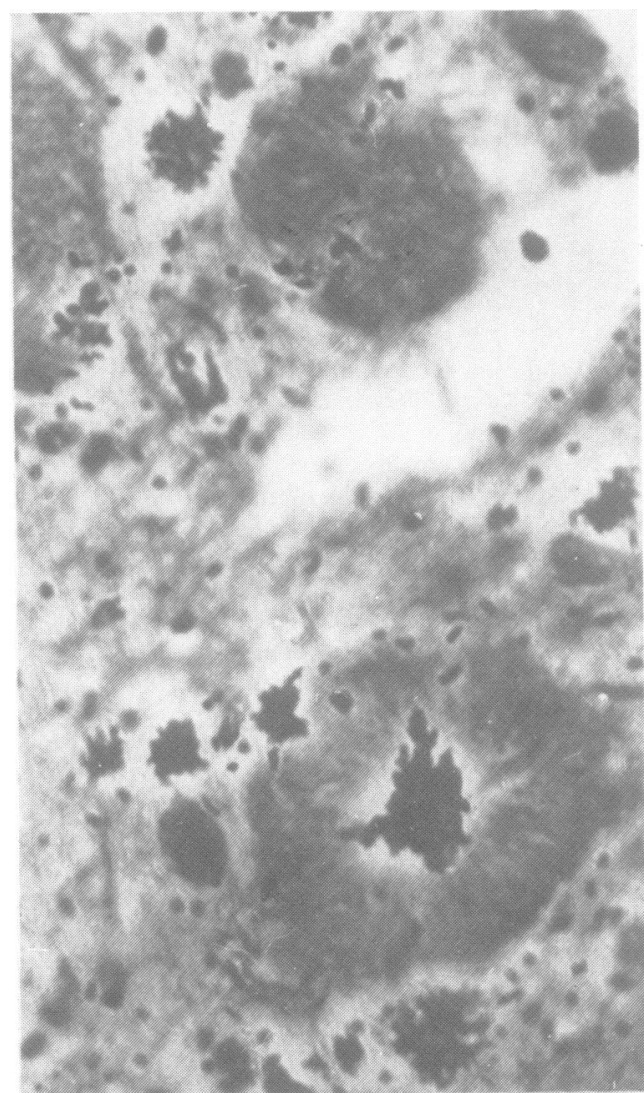

Fig 10 Case 1 Two atypical plaques in hippocampus, with radiating fibrils. These are surrounded by irregular argyrophilic masses, resembling the dense core of the large plaque. von Braunmühl, $\times 570$.

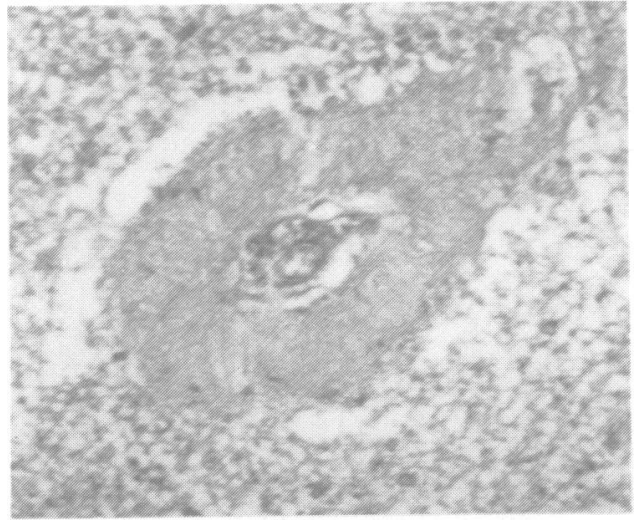

Fig 11 Case 1 A "plaque", with radiating fibrils, surrounding a small vessel in the hippocampus. Luxol blue with PAS, $\times 475$.

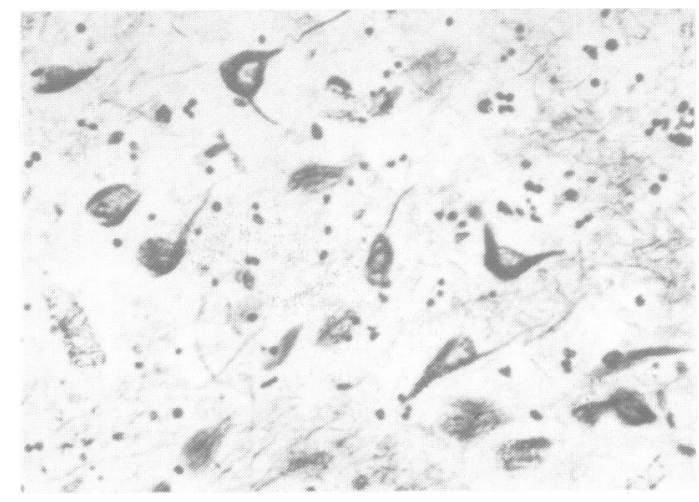

Fig 12 Case 1 Nerve cells in $h_{2}$ sector of hippocampus, showing neurofibrillary tangles. von Braunmühl, $\times 180$. 


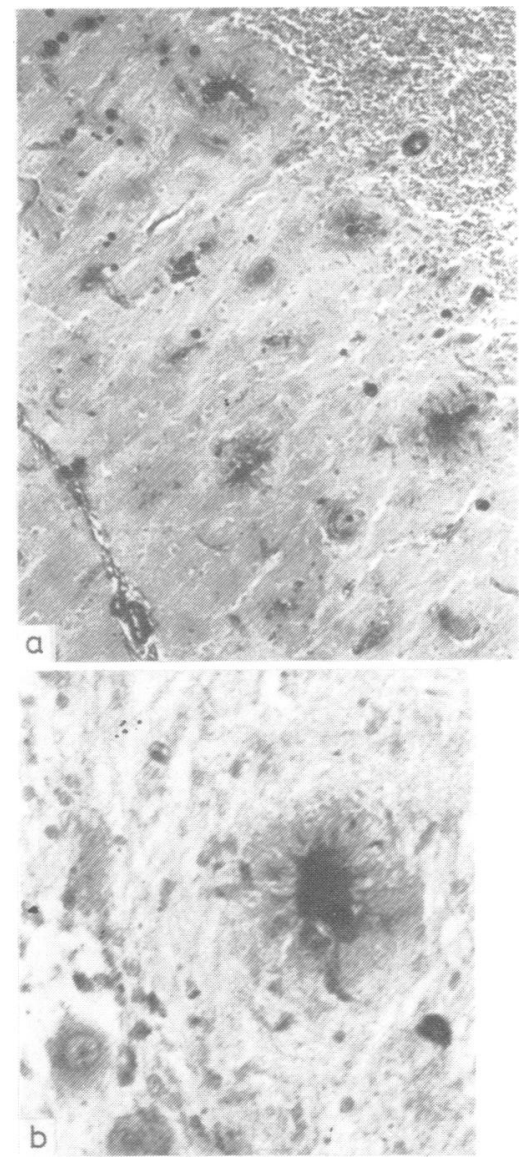

Fig 13 Case 2 Perivascular "plaques", with radiating spicules, in cerebellar cortex. PAS (a) $\times 75$, (b) $\times 240$.

Plaques of type A (above) were also abundant in the cerebellar cortex, some having densely-staining amyloid cores, others not. Whether these were in fact of different structure from the type $C$ plaques was not easy to decide. Their staining was similar; where no core was seen, this might be due to the plane of section, and where a core was present, it could be suspected of representing a degenerate capillary vessel.

Plaques of the type characteristic of Alzheimer's disease were not seen. A few cortical cells showed neurofibrillary tangles. The brainstem and spinal cord showed minimal loss of myelin in the corticospinal tracts. There was a mild cell loss-presumably retrograde-in the right inferior olive, whereas the left olive appeared intact. There was a patchy drop-out of Purkinje cells, of nerve cells in the dentate nuclei, and of myelinated fibres in the superior cerebellar peduncles. These changes suggested ischaemic damage rather than primary neuronal degeneration.

In summary, there was congophilic angiopathy, less severe than in case 1 , producing relatively mild ischaemic changes in the nervous tissue; and widespread congophilic plaques, often related to small blood vessels, and associated with diffuse degenerative changes in the cerebral and cerebellar white matter.

\section{Discussion}

The two patients described here suffered from a disease of the vasculature of the central nervous system, commonly called "congophilic (or amyloid) angiopathy". Apart from the various types of "plaque" described above, the lesions in the brain are all attributable to occulusion of, or bleeding or leakage from, diseased blood vessels. There is no clear evidence of any primary degeneration of the nervous parenchyma. Thus there is prima facie justification for separating these cases from cases of Alzheimer's disease, in which cortical neurons are altered or lost in the absence of any apparent deficiency in their blood supply.

Although cases which were almost certainly instances of congophilic angiopathy were described in the early years of this century, it was not until the nineteen thirties and forties that the chemical and histological features of the condition began to be closely studied. Interest in the condition seems to have converged from two directions-from psychiatrists concerned with the causes of dementia on the one hand, and from pathologists concerned with vascular lesions on the other. Most notable in the first group was Paul Divry, who from 1927 onward studied the histochemical changes in the brains of old people, and in particular in cases of senile and presenile dementia. He demonstrated the presence of amyloid in the centres of so-called senile plaques, ${ }^{3}$ in Alzheimer's neurofibrillary tangles ${ }^{4}$ and in the walls of small cortical and meningeal blood vessels. ${ }^{5}$ A synthesis of this work was published ten years later. ${ }^{6}$ Scholz in $1938^{7}$ described findings closely similar to Divry's. Among 104 consecutive necropsies on patients aged 70 or over, he observed vascular changes, other than those of atherosclerosis, in 15 brains. The changes included the deposition, in the medial walls of cortical and meningeal arterioles, of a substance with the staining reactions of amyloid, indistinguishable from the amyloid cores of senile plaques. The same material could often be seen spreading into the adventitia, and through the walls of capillaries into the surrounding parenchyma. Scholz described the changes as drusige Entartung der Hirnarterien und capillaren. (Drusen is a rare word, applied to senile plaques in the German literature since the early part of the century. Scholz ${ }^{7}$ on p 695 refers to die Substanz, aus welchen sich die Plaques oder Drusen im senilen Gehirn aufbauen, and proceeds to show that the same substance is seen in and around the walls of 
diseased blood vessels. Some subsequent authors (having failed, presumably, to find the word Drusen in their dictionaries) have mistakenly written drüsige Entartung, which would mean "glandular degeneration".) The histochemistry of the vessels in senile and demented brains was further studied by Morel and Wildi. ${ }^{8}$ Their findings agreed with those of Scholz, but they considered that the term drusige Entartung was untranslatable, and proposed as an alternative "dyshoric angiopathy"-the word "dyshoric" implying a breakdown of the blood-brain barrier. The term "dyshoric angiopathy" was later used by Surbek $^{9}$ in an account of 79 instances, all from senile brains. Surbek pointed out the preferential involvement of the fourth layer of the striate area in the occipital cortex in this condition, unassociated with focal anoxic or degenerative changes in nerve cells. In every case, senile plaques were present in the cortex, though the distribution of plaques was not directly related to the distribution of the vascular changes. There was no apparent association with disease elsewhere in the body; and no regular relation between the angiopathy and recorded neuropsychiatric disturbances. In two families there were affected siblings. Surbek's paper includes a valuable historical review of the subject. The term drusige Entartung was used again by Schlote, ${ }^{10}$ who gave detailed histological and electronmicroscopic descriptions of a case; but today this term, and the term "dyshoric angiopathy" seem to have fallen out of use, in favour of "congophilic angiopathy" 11 or "cerebral amyloid angiopathy" 1213 or, as an alternative, "primary cerebrovascular amyloidosis". ${ }^{14}$

The main points established in these and other studies are: (1) congophilic angiopathy is common, but not always present, in Alzheimer's disease. (2) it is not uncommon in non-demented old people, and becomes commoner with advancing years. ${ }^{7815}(3)$ it is almost invariably associated with the presence of senile plaques in the cerebral cortex. (4) it is not related to arterial hypertension, ${ }^{16}$ to atherosclerosis, or to generalised amyloidosis, primary or secondary. (5) it is very rarely diagnosed clinically. (6) the pathogenesis of the vascular lesions, as well as of the senile plaques, remains obscure. ${ }^{1317-19}$

Congophilic angiopathy, as described by the foregoing authors, is a relatively mild condition and rarely leads to major cerebral disasters. ${ }^{20-25}$ There are, however, at least two conditions in which this is not the case. The first is a familial disease recently reported from Iceland. ${ }^{26}$ The patients, in the prime of life, suffer fatal cerebral haemorrhages. Necropsies have shown cerebral amyloid angiopathy, without systemic amyloidosis, and without senile plaques or neurofibrillary tangles. Apart from the amyloid angiopathy, these cases have little or nothing in common either with Alzheimer's disease or with cases such as the ones we describe here. The other condition in which severe cerebral vascular lesions-namely, haemorrhages, softenings and rarefactions - appear to be due to cerebral amyloid angiopathy was first described in detail by Worster-Drought, Greenfield and McMenemey in $1940^{1}$ and $1944 .^{2}$ These authors described a family in which 10 members were known to have suffered from a progressive paralysis, usually associated with dementia, with onset in middle age. A brother and sister from this family came to necropsy, and were found to have similar lesions in the brain and spinal cord, consisting of "hyaline" and other changes in small blood vessels, and "plaques", up to $100 \mu \mathrm{m}$ (exceptionally, up to $150 \mu \mathrm{m}$ ) in diameter, in Ammon's horns and in the cerebellar cortex. These "plaques" differed in their form and staining reactions from conventional "senile plaques", which were also present, but confined to Ammon's horns. In addition, there were widespread small softenings and rarefactions and, in one of the cases, old haemorrhages. Although amyloid was not originally looked for, McMenemey later ${ }^{27}{ }^{28}$ expressed his conviction that both patients had suffered from congophilic angiopathy. From the detailed descriptions and excellent photographs in these two papers it would be hard to doubt that the lesions, and the underlying disease, are identical in their cases and in ours.

Subsequent reports of cases more or less resembling these are those of van Bogaert, Maere and Smedt, ${ }^{29}$ Lüers, ${ }^{30}$ Corsellis and Brierley, ${ }^{31}$ Neumann, ${ }^{32}$ Hollander and Strich ${ }^{33}$ and Gerhard, Bergener and Homayun. ${ }^{34}$ The accompanying table shows the main clinical and pathological features of these 12 cases, including our own. Among these 12 there are conspicuous differences from case to case, and it is by no means certain that they form a homogeneous group. In the first place, in nine cases there is good evidence for autosomal dominant transmission, but in cases 7,8 , and 9 there is not. Progressive dementia was a major feature in 10 cases, but did not occur in cases 8 and 9. All of them showed severe congophilic angiopathy, unassociated with amyloidosis elsewhere in the body; but the severity of this and its distribution (for instance to the vessels of the brainstem and spinal cord) varied greatly. Atypical plaques were seen in every case, but their distribution showed marked differences. They were present in the cerebellum in cases $1,2,3$, 9,11 and 12 but not in the others. Neurofibrillary tangles, with a form, frequency and distribution suggestive of Alzheimer's disease, were present in cases $3,4,6$ and 10; confined to Ammon's horn in cases 1 , 2,9 and 11; and absent in case 8 . 


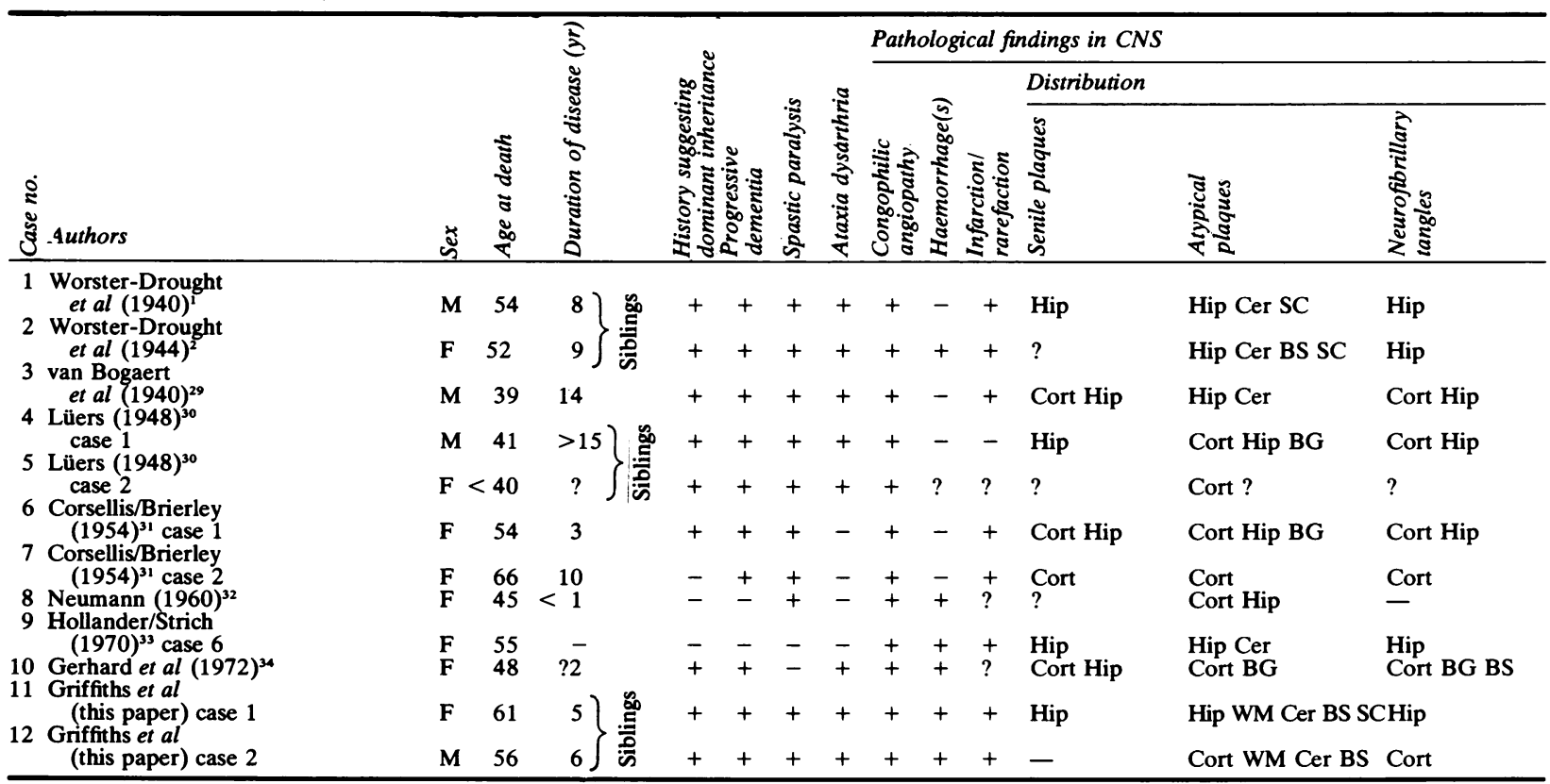

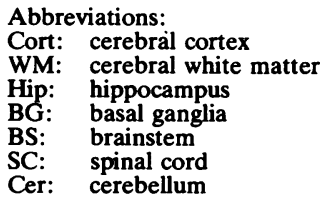

The authors of the published reports do not agree on the naming of the disease. Worster-Drought et al, ${ }^{1}$ call it "familial presenile dementia with spastic paralysis". They discuss points of resemblance with other diseases, including Alzheimer's disease, but remark (p 249): "It is noteworthy that this patient exhibited the neurofibrillary changes with which we are familiar in Alzheimer's disease and in senile dementia, but their prevalence was considerably less and indeed, beyond the fact that both Alzheimer's disease and the case we are discussing indicate a severe disorder of the brain metabolism, no resemblance either clinically or histologically can be drawn between them". They also observe that although some of the "plaques" in their case resembled the familiar form of "senile plaque" seen in Alzheimer's disease, many of them differed so much in their form and their distribution that they must be regarded as different structures. Their views were supported by Neumann ${ }^{32}$ who considered her case to be of the same type as theirs, although it differed clinically. The remaining authors, in contrast, have stressed the resemblances with Alzheimer's disease, as can be seen from the titles of their papers. The disease is call Precocious (or juvenile) Alzheimer's disease by van Bogaert $e t a^{29}$ and by Lüers; ${ }^{30}$ and Atypical Alzheimer's disease by Corsellis and Brierley ${ }^{31}$ and by Gerhard et al. ${ }^{34}$ As we know so little of the aetiology of any of these conditions, we shall make no attempt at a definitive classification. We propose merely to draw attention to a few relevant considerations.

First, there is the working definition of Alzheimer's disease, in which we include, for present purposes, so-called senile dementia. Clinically, there is a progressive dementia, starting in the fifth or later decades, with variable symptoms, neurological signs, speed of deterioration and total duration. Pathologically, there are widespread "senile plaques" and neurofibrillary tangles in the cerebral cortex, including the hippocampus, and granulovacuolar degeneration in pyramidal cells of the hippocampus. An inconstant feature is congophilic angiopathy of small meningeal and intracortical blood vessels. ${ }^{12}$ 
This is usually of mild degree, but is sometimes severe enough to result in focal softenings and haemorrhages. ${ }^{22}$ Similar lesions have been found in elderly patients, not fulfilling the criteria for Alzheimer's disease in that neurofibrillary tangles were absent or sparse and limited to the hippocampus. ${ }^{21} 2425$ Although they had progressive dementia they differed from the patients we describe in that they did not have plaques of type $C$ and no family history was noted.

Neurofibrillary tangles may be found in sites other than cerebral cortex; and in some cases the lesions of other diseases, such as Parkinson's disease, may be present alongside those of Alzheimer's disease. ${ }^{35}$ Disregarding these, so to speak optional extras, it would be reasonable to restrict the diagnosis of Alzheimer's disease to patients with dementia, in whose brains senile plaques and neurofibrillary tangles are widely distributed in the cerebral cortex. Cases of this type usually occur sporadically. Familial cases have been described, including some in which the disease appears to be transmitted as an autosomal dominant. ${ }^{36}$ No consistent differences, either clinical or pathological, are described as between sporadic and familial cases.

Using these simple criteria, we may enquire whether the cases listed in the table merit the label of Alzheimer's disease, typical or atypical. We have already quoted the reasons given by WorsterDrought $e a^{1}$ for rejecting this diagnosis. The same considerations apply generally to our two cases. Many of the "plaques" appear to be of different structure and chemical composition from those seen in Alzheimer's disease, and "typical" plaques are not generally distributed through the cerebral cortex, but practically confined to the hippocampus; while the lesions in the cerebellar cortex, which are such a prominent feature in our cases, as in those of Worster-Drought et al, have rarely been seen in Alzheimer's disease. ${ }^{37}$ The two cases ${ }^{32} 33$ in which dementia did not occur do not qualify for the title of Alzheimer's disease, typical or atypical. Here we are faced with a clear choice; either these two cases do not belong to the same group of diseases as the rest, or Alzheimer's disease is not an appropriate diagnosis for the group as a whole.

The two pathological features that appear to bind these 12 cases together, and to separate them from other diseases of the CNS, are (1) a severe congophilic angiopathy, confined to the CNS and (2) the presence of large atypical amyloid-containing "plaques" differing from the more familiar "senile plaques" in their form, staining properties and distribution. The origin and significance of these "plaques", and their relation to senile plaques, remains unknown. Similar structures have been observed, unassociated with congophilic angiopathy, in a rare familial disease described by Seitelberger ${ }^{38}$ and by Boellaard and Schlote. ${ }^{39}$ The main clinical features of this condition are a severe progressive cerebellar ataxia followed by other neurological disturbances, including organic dementia. Boellaard and Schlote ${ }^{39}$ describe various kinds of amyloid-containing "plaques" in their two unrelated cases. Of these, the kind which they call "primitive plaques" closely resemble the atypical plaques in the present series.

It has been suggested ${ }^{34} 40$ that congophilic angiopathy of the brain may be in some way related to rheumatoid disease. In the two cases reported here, there was no evidence of such disease except that in both patients there was a noteworthy kyphoscoliosis. In case 2 the ESR was reported as normal.

A logical classification of the various conditions in which amyloid is deposited in or around the brain is not possible. Clinical considerations are of little help. The dementia, which is a prominent feature of most, but not all, of these conditions, may be attributed to a primary neuronal degeneration or to vascular accidents, or to a combination of these. Other neurological signs, such as weakness, stiffness and ataxia, are often explicable simply by reference to the sites of vascular lesions rather than to the nature of the pathological process. In the taxonomy of animal and vegetable species there are no clear-cut rules defining the difference between a "species" and a "variety". The distinction is made largely on the basis of common sense and convenience. The same applies to the classification of diseases. We think, as against a number of distinguished and learned predecessors, that common sense and convenience demand a firm separation of our cases of cerebral amyloid angiopathy from the category of Alzheimer's disease. We are supported in this by a recent article ${ }^{41}$ describing a severe cerebral amyloid angiopathy with perivascular spread and atypical plaque formation, affecting especially the cerebellar cortex, in a 14-year-old boy with a 4-year history of progressive dementia. Nobody, presumably, would suggest that this child was suffering from premature Alzheimer's disease; yet there is more in common between this case and the cases we have been discussing than there is between our cases and classical Alzheimer's disease. Until more is known of the aetiology of both conditions it will be prudent to give them different labels. The term "cerebral amyloid (or congophilic) angiopathy" is already in use, and should be preserved, the only objection being that the disease (unlike classical Alzheimer's disease) affects more than the cerebral hemispheres. In present usage, "cerebral" has come to mean "of the brain as a whole". It remains to be seen whether 
the primary abnormality lies in the brain parenchyma, or in its blood vessels, or in the blood, or elsewhere.

We are grateful to Dr NJH Davidson, who performed the necropsy on case 1 and sent the brain and spinal cord; and to Drs JD Craig and PS Bhatia for valuable clinical information in case 1 .

\section{References}

${ }^{1}$ Worster-Drought C, Greenfield JG, McMenemey WH. A form of familial presenile dementia with spastic paralysis. Brain 1940;63:237-54.

${ }^{2}$ Worster-Drought C, Greenfield JG, McMenemey WH. A form of familial presenile dementia with spastic paralysis. Brain 1944;67:38-43.

${ }^{3}$ Divry P. Etude histo-chimique des plaques seniles. $J$ Belge Neurol Psychiatr 1927;27:643-57.

4 Divry P. De la nature de l'alteration fibrillaire d'Alzheimer. J Belge Neurol Psychiatr 1934; 34:197-201.

${ }^{5}$ Divry P. De l'amyloïdose vasculaire cérébrale et méningée (méningopathie amylö̈de) dans la démence sénile. J Belge Neurol Psychiatr 1941-42;4142:141-58.

- Divry P. La pathochimie générale et cellulaire des processus séniles et préséniles. Proc 1st Int Cong Neuropath Rome vol 2. Turin: Rosenberg and Sellier, 1952:313-45.

' Scholz W. Studien zur Pathologie der Hirngefásse II; Die drusige Entartung der Hirnarterien und -capillaren. Z ges Neurol Psychiat 1938;162:694-715.

- Morel F, Wildi E. General and cellular pathochemistry of senile and presenile alterations of the brain. Proc 1st Int Cong Neuropath Rome vol 2. Turin: Rosenberg and Sellier, 1952:347-74.

9 Surbek B. L'angiopathie dyshorique (Morel) de l'écorce cérébrale. Acta Neuropathol (Berl) 1961;1:168-97.

${ }^{10}$ Schlote W. Die Amyloidnatur der kongophilen, drusigen Entartung der Hirnarterien (Scholz) im Senium. Acta Neuropathol (Berl) 1965;4:449-68.

${ }^{11}$ Pantelakis S. Un type particulier d'angiopathie sénile du système nerveux central: l'angiopathie congophile. Topographie et frequence. Mtsschr Psych Neurol 1954;128:219-56.

${ }^{12}$ Mandybur TI. The incidence of cerebral amyloid angiopathy in Alzheimer's disease. Neurology (Minneap) 1975;25:120-6.

${ }^{13}$ Mandybur TI. Cerebral Amyloid Angiopathy. In: Glenner CG, Pinho e Costa P, de Freitas AF, eds. Amyloid and Amyloidosis. Third International Symposium on Amyloid. Amsterdam: Excerpta Medica 1980:231-8.

${ }^{14}$ Okazaki H, Reagan TJ, Campbell RJ. Clinicopathologic studies of primary cerebral amyloid angiopathy. Mayo Clin Proc 1979;54:22-31.

${ }^{15}$ Wright JR, Calkins E, Breen WJ, Stolte G, Schultz RT. Relationship of amyloid to aging. Review of the literature and systematic study of $\mathbf{8 3}$ patients derived from a general hospital population. Medicine (Baltimore) 1969;48:39-60.
${ }^{16}$ Gerhard L. Zur Frage der Abgrenzung hypertonischer Encephalopathien von kongophiler Angiopathie bei seniler Demenz oder "atypischer" Alzheimerscher Krankheit. I-Donau-Symposium für Neuropathologie. Wien: Mediz Akad 1969:87-92.

17 Glenner CG. Current knowledge of amyloid deposits as applied to senile plaques and congophilic angiopathy. In: Katzman R, Terry RD, Bick KL, eds. Alzheimer's Disease: Senile Dementia and Related Disorders. Ageing 7. New York: Raven Press 1978: 493-502.

${ }^{18}$ Glenner CG. Congophilic microangiopathy in ${ }^{-}$the pathogenesis of Alzheimer's syndrome (presenile dementia). Medical Hypotheses 1979;5:1231-6.

19 Torack RM, Lynch RG. Cytochemistry of brain amyloid in adult dementia. Acta Neuropathol (Berl) 1981;53:189-96.

${ }^{20}$ Ulrich G, Taghavy A, Schmidt H. Zur Nosologie und Ätiologie der kongophilen Angiopathie (Gefässform der cerebralen Amyloidose). Z Neurol 1973; 206:39-59.

${ }^{21}$ Torack RM. Congophilic angiopathy complicated by surgery and massive haemorrhage. Am J Pathol 1975;81:349-66.

22 Jellinger K. Cerebrovascular amyloidosis with cerebral haemorrhage. J Neurol 1977;214:195-206.

${ }^{23}$ Mandybur TI, Stephen RD, Bates MD. Fatal massive intracerebral haemorrhage complicating cerebral amyloid angiopathy. Arch Neurol 1978;35:246-8.

${ }^{24}$ Lee S-S, Stemmermann GN. Congophilic angiopathy and cerebral haemorrhage. Arch Pathol Lab Med 1978;102:317-21.

${ }^{25}$ Okazaki H, Reagan TJ, Campbell RJ. Clinicopathological studies of primary amyloid angiopathy. Mayo Clin Proc 1979;54:22-31.

${ }^{26}$ Gudmundsson G, Hallgrimmsson J, Jónasson TA, Bjarnason $O$. Hereditary cerebral haemorrhage with amyloidosis. Brain 1972;95:387-404.

${ }^{27}$ McMenemey WH. Discussion. In: Proc 1st Int Congr Neuropath Rome vol 2. Turin: Rosenberg and Sellier 1952:432-6.

${ }^{28}$ McMenemey WH. Discussion. In: Wolstenholme GEW, O'Connor M, eds. Alzheimer's Disease and Related Conditions. London: Churchill 1970:132-3.

${ }^{29}$ Bogaert $L$ van, Maere M, Smedt $E$ de. Sur les formes familiales précoces de la maladia d'Alzheimer. Mtsschr Psychiat Neurol 1940;102:249-301.

${ }^{30}$ Lüers $T$. Uber die familiăre juvenile Form der Alzheimerschen Krankheit mit neurologischen Herderscheinungen. Arch Psychiat Nervenkr (Z Neurol Psychiat) 1947;179:132-45.

${ }^{31}$ Corsellis JAN, Brierley JB. An unusual type of presenile dementia (atypical Alzheimer's disease with amyloid vascular change). Brain 1954;77:571-87.

${ }^{32}$ Neumann MA. Combined amyloid vascular changes and argyrophilic plaques in the central nervous system. $J$ Neuropath Exp Neurol 1960;19:370-82.

${ }^{33}$ Hollander D, Strich SJ. Atypical Alzheimer's disease with congophilic angiopathy presenting with dementia of acute onset. In: Wolstenholme GEW, O'Connor M, eds. Alzheimer's Disease and Related Conditions. London: Churchill, 1970:105-24.

${ }^{34}$ Gerhard L, Bergener M, Homayun S. Angiopathie bei 
Alzheimerscher Krankheit. Z Neurol 1972;201:4361.

${ }^{35}$ Boller F, Mizutani T, Roessmann U, Gambetti P. Parkinson disease, dementia and Alzheimer disease: clinicopathological correlations. Ann Neurol 1980;7:329-35.

${ }^{36}$ Cook RH, Ward BE, Austin JH. Studies in aging of the brain: IV. Familial Alzheimer disease. Neurology (Minneap) 1979;29:1402-12.

${ }^{37}$ Pro JD, Smith CH, Sumi SM. Presenile Alzheimer disease: amyloid plaques in the cerebellum. Neurology (Minneap) 1980;30:820-5.
${ }^{38}$ Seitelberger F. Eigenartige familiăr-heredităre Krankheit des Zentralnervensystems in einer niederösterreichischen Sippe. Wien Klin Wschr 1962;4142:687-91.

${ }^{39}$ Boellaard JW, Schlote W. Subakute spongiforme Encephalopathie mit multiformer Plaquebildung. Acta Neuropathol (Berl) 1980;49:205-12.

${ }^{40}$ Mandybur TI. Cerebral angiopathy. Possible relationship to rheumatoid vasculitis. Neurology (Minneap) 1979;29:1336-40.

${ }^{4}$ Shaw C-M. Primary idiopathic cerebrovascular amyloidosis in a child. Brain 1979;102:177-92. 